\title{
Influence of Certain Nutrients on Changes in Adipose and Dental Tissues of Vitamin E-Deficient Rats
}

\author{
By H. GRANADOS, E. AAES-JØRGENSEN AND H. DAM \\ Department of Biology, Polytechnic Institute, Copenhagen, Denmark
}

(Received I6 August 1949)

It has been shown that certain symptoms in chicks, namely, exudative diathesis, yellow coloration of the adipose tissue, and encephalomalacia, and in rats, namely, yellowbrown coloration of the adipose tissue, and depigmentation of the incisors, depend upon the consumption of vitamin E-deficient diets rich in highly unsaturated fatty acids (Dam, 1944a, $b$; Dam \& Granados, I945 $a, b$; Granados \& Dam, 1945 $a, b$; Granados, Mason \& Dam, 1945, 1946). Formation of peroxides preceded, and in some instances paralleled, the brown coloration in the adipose tissue of these animals (Dam \& Granados, I $945 a, b$ ). The pigment responsible for the coloration of the adipose tissue was found to consist of at least two fractions: one of them is fat-soluble, and the other, which occurs in larger amounts, is not extracted by lipid solvents (Dam \& Granados, I945a).

Histologically, the main pigment (fat-insoluble fraction) of the adipose tissue was found to be represented by an acid-fast pigment in the fat cells at different stages of development. The histopathological changes in the adipose and other tissues were studied to a certain extent (Dam \& Mason, I945; Mason, Dam \& Granados, r946; Granados et al. 1947). Moreover, a method for the histochemical demonstration of fat peroxides has been developed (Glavind, Granados, Hartmann \& Dam, 1949), and applied to the study of the relationship between peroxides and the formation of the acid-fast pigment in the adipose tissue of vitamin E-deficient rats (Granados, Glavind, Hartmann \& Dam, 1950).

Furthermore, since depigmentation of the incisors is a symptom important in the investigation of the metabolic role of vitamin $E$, a method for evaluating the degree of depigmentation of the enamel in vitamin E-deficient rats was developed (Granados \& Dam, I948).

Dam, Granados \& Prange (1949) studied the influence of two different fats (lard and cod-liver oil) on the reproductive capacity of vitamin E-deficient rats. They found an apparent difference in reproductive performance: that of the animals given the diet containing cod-liver oil was affected to a much larger extent than that of the rats given the ration containing lard. The authors pointed out that the peroxidation of the highly unsaturated fatty acids of cod-liver oil in absence of the antioxidant effect of vitamin $\mathrm{E}$ may have been responsible for the difference in reproductive performance, and suggested that the sterility symptom in vitamin $\mathrm{E}$ deficiency may be causally related to the peroxidation of highly unsaturated fatty acids. On the other hand, Dam, Kruse, Prange \& Søndergaard (1948) showed that the exudative diathesis produced in chicks 
by diets rich in highly unsaturated fatty acids and low in vitamin $\mathrm{E}$ can be counteracted to a considerable extent by the addition of $0.5 \%$ ascorbic acid, nordihydroguaiaretic acid or cystine to the diet. Furthermore, they found that encephalomalacia produced by diets low in vitamin $\mathrm{E}$ can be counteracted by the addition of $0.5 \%$ ascorbic acid but not by a corresponding amount of cystine.

We have carried out three series of experiments in order to study further the influence of certain nutrients on the changes in adipose and dental tissues reviewed above, i.e. peroxidation and coloration of the adipose tissue, and depigmentation of the incisors. We report here the results of these investigations.

\section{METHODS}

In all three series of experiments newly weaned rats were used. They were given the rations as well as tap water ad lib. for a 70-day experimental period, and were weighed weekly. Likewise, from the 3 rd experimental week the degree of depigmentation of the enamel in the various groups was recorded, using the method referred to above (Granados \& Dam, I948). At the end of the experimental period the animals were killed, and the colour of their lumbar fat depots was recorded, using a colour scale from $\circ$ to 5, 0 indicating no colour, $I$ pale yellow, 2 yellow, 3 dark yellow, 4 yellowbrown, and 5 dark yellow-brown colour. Samples of lumbar fat were then taken for the determination of peroxides by the method of King, Roschen \& Irwin (1933) as modified by Dam \& Granados ( $1945 a$ ), and by the method of Hartmann \& Glavind (1949).

First series of experiments. In the first series $\mathrm{I}$ Io female rats were distributed into eleven equal groups and were given the vitamin E-deficient diets presented in Table I. Table 2 presents the various salt mixtures used. In this series a vitamin E-deficient diet containing $25 \%$ alcohol-extracted casein, $5 \%$ McCollum's salt mixture no. 185 , and $20 \%$ cod-liver oil was used as control, and the following studies were made: ( $\mathrm{I}$ ) comparison between crude and alcohol-extracted casein, using two different types of yeast, and pure B-vitamins; (2) comparison of three levels of alcohol-extracted casein; (3) comparison of three different salt mixtures; and (4) study of the effect of $0.1 \%$ xanthine.

Second series of experiments. In the second series 112 male rats were distributed into fourteen equal groups, and were reared on the rations presented in Table 5. In this series a vitamin E-deficient diet containing $18 \%$ alcohol-extracted casein, $5 \%$ McCollum's salt mixture no. 185 , and $20 \%$ cod-liver oil was used as control, and the following studies were made: (1) a study of the effect of $0.5 \%$ cystine, $0.6 \%$ methionine, $0.5 \%$ ascorbic acid, $0.5 \%$ inositol, and $0.5 \%$ nordihydroguaiaretic acid, as compared with the effect of $0 \cdot 0 r \% \alpha$-tocopherol acetate; (2) comparison of the effect of supplementing McCollum's salt mixture with the following elements, or combinations of them: iodine and manganese; iodine, manganese and copper; iodine and copper; manganese and copper; iodine, manganese or copper. Furthermore, in this series an additional group of ten castrated males was reared in order to study any possible influence of orchidectomy upon the development and progress of the symptoms under study. 
Table I. Percentage composition of diets given to groups I-I I in the first series of experiments

(The composition of the salt mixtures is shown in Table 2.)

\begin{tabular}{|c|c|c|c|c|c|c|c|c|c|c|c|}
\hline \multirow[b]{2}{*}{ Ingredient } & \multicolumn{11}{|c|}{ Group no. } \\
\hline & I & 2 & 3 & 4 & 5 & 6 & 7 & 8 & 9 & I0 & I I \\
\hline $\begin{array}{l}\text { Vitamin K (Synkavit, } \\
\text { F. Hoffmann-La Roch } \\
\text { \& Co.) }\end{array}$ & he & 0.001 & 0.001 & - & 0.001 & - & - & - & $\rightarrow$ & - & - \\
\hline Xanthine & - & - & - & - & - & - & - & - & - & - & 0.1 \\
\hline Choline chloride & - & - & - & 0.4 & - & 0.4 & 0.4 & 0.4 & 0.4 & 0.4 & 0.4 \\
\hline $\begin{array}{l}\text { Casein: alcohol ex- } \\
\text { tracted }\end{array}$ & 20 & - & - & - & 20 & 25 & 15 & 35 & 25 & 25 & 25 \\
\hline Casein : crude & - & 20 & 20 & 25 & - & - & - & - & - & - & - \\
\hline $\begin{array}{l}\text { Yeast: A, ether-ex- } \\
\text { tractedt }\end{array}$ & 10 & 10 & - & - & 一 & - & - & - & - & - & - \\
\hline $\begin{array}{l}\text { Yeast: B, ether-ex- } \\
\text { tracted } f\end{array}$ & - & - & 10 & - & 10 & - & - & - & - & - & - \\
\hline Vitamin mixture§ & - & - & - & 0.5 & - & 0.5 & 0.5 & 0.5 & 0.5 & 0.5 & 0.5 \\
\hline Cod-liver oil|| & 20 & 20 & 20 & 20 & 20 & 20 & 20 & 20 & 20 & 20 & 20 \\
\hline Salt mixture no. I & 5 & 5 & 5 & 5 & 5 & 5 & 5 & 5 & - & - & 5 \\
\hline Salt mixture no. 2 & - & - & - & - & - & - & - & - & - & 5 & - \\
\hline Salt mixture no. 3 & - & - & - & - & - & - & - & - & 5 & - & - \\
\hline Sucrose & 45 & 45 & 45 & $49 \cdot I$ & 45 & I & $59 \cdot \mathrm{I}$ & $39^{\cdot I}$ & $49 \cdot I$ & $49 \cdot 1$ & 49 \\
\hline $\begin{array}{l}\text { 'Vitamin-test' case } \\
\text { ' Fleischmann yeast } \\
\text { I Medicinalco yeast } \\
\$ \text { The } 0.5 \mathrm{~g} \text {. of vita } \\
5 \mathrm{mg} \text {., ribofiavin } 5 \mathrm{mg} \\
7.5 \mathrm{mg} ., \text {-aminobenzoi } \\
\text { || Addded fresh every }\end{array}$ & $478 \mathrm{I}$ & en & Bioch & $\mathrm{C}$ & $\begin{array}{l}c ., \mathrm{C} \\
\text { w Y } \\
\text { nhag } \\
\mu \mathrm{g} . \\
\text { cal } \\
\text { itam }\end{array}$ & $\operatorname{rin}$ & 8 , & mg & .A. & & $\mathrm{mg}$ \\
\hline
\end{tabular}

Table 2. Composition of the different salt mixtures used in the three series of experiments

Amounts of additions to $100 \mathrm{~g}$. of McCollum's salt mixture no. 185 (salt mixture no. I)

$\begin{array}{cccc}\begin{array}{c}\text { Salt mixture } \\ \text { no. }\end{array} & \begin{array}{c}\mathrm{KI} \\ \text { (mg.) }\end{array} & \begin{array}{c}\mathrm{MnSO}_{4} \cdot 4 \mathrm{H}_{2} \mathrm{O} \\ (\mathrm{mg})\end{array} & \begin{array}{c}\mathrm{CuSO}_{\mathbf{4}} \cdot 5 \mathrm{H}_{2} \mathrm{O} \\ (\mathrm{mg} .)\end{array} \\ \mathrm{I} & - & - & - \\ 2 & 13.5 & 556 & - \\ 3 & 13.5 & 556 & 139 \\ 4 & 13.5 & 556 & 139 \\ 5 & 13.5 & - & - \\ 6 & - & 556 & 139 \\ 7 & - & - & 139\end{array}$

Third series of experiments. In the third series twenty-one male and twenty-eight female rats were distributed into seven groups (three males and four females in each) and reared on the diets presented in Table 8. In this experiment a comparison was made between the effects of no fat, lard and cod-liver oil using a vitamin E-deficient diet low in protein (10\% crude, or alcohol-extracted, casein). 


\section{RESULTS}

First series of experiments. Table 3 shows the results of the comparison of crude with alcohol-extracted casein, using two different types of yeast and pure B-vitamins. It can be seen from this table that alcohol-extracted instead of crude casein, at a level of $25 \%$, did not increase significantly either peroxidation or the yellow-brown coloration of the adipose tissue in any of the groups. Furthermore, the use of two different types of yeast, or of pure B-vitamins, did not bring about any difference in the extent to which these symptoms developed. Crude casein (groups 2 and 3 ) gave partial protection against depigmentation of enamel as compared with alcoholextracted casein (groups $I$ and 5). It can also be noted that the fat coloration and peroxidation of a group exhibiting a low degree (group 3), and one exhibiting a high degree (group 6), of depigmentation of enamel, may be essentially the same. Furthermore, it should be remarked that in several instances animals developed marked degrees of coloration and peroxidation of fat without exhibiting any degree of dental depigmentation.

Table 4 shows the results of comparisons between three different levels of alcoholextracted casein and between three different salt mixtures, and the effect of the addition of $0.1 \%$ xanthine. It can be seen that the depigmentation of the incisors was more marked with the lowest level ( $15 \%$ ) of casein (group 7) than with $25 \%$ (group 6) and $35 \%$ (group 8 ) casein. It should be noted that this increased dental depigmentation brought about in group 7 by lowering the protein level was accompanied by a decrease of peroxidation and coloration of fat. On the other hand, the coloration of the adipose tissue was somewhat more pronounced (grade 3 ) in the animals which received $25 \%$ casein (group 6) than in the rats given either $15 \%$ (group 7 ) or $35 \%$ (group 8) casein.

It can be seen that salt mixtures 2 (McCollum's 185 with iodine and manganese, group ro) and 3 (McCollum's 185 with iodine, manganese and copper, group 9) gave marked protection against tooth depigmentation as compared with the effect of salt mixture I (McCollum's 185 alone, group 6), but there was no difference in peroxide values or in coloration of fat between the three groups. This shows that certain elements may protect against depigmentation of the enamel without altering the degree of peroxidation and coloration of fat.

Table 4 shows, finally, that the addition of $0.1 \%$ xanthine (group II) to a vitamin E-deficient diet containing $25 \%$ casein (group 6) did not protect against any of the three manifestations under study. Furthermore, in this experiment xanthine did not improve the growth of the animals.

Second series of experiments. Table 5 presents the rations given to the fourteen groups which comprised the second series. Table 6 compares the action of certain substances (groups $13-17$ ) in the prevention of the manifestations under study with the effect of $\alpha$-tocopherol acetate (group 18), an unsupplemented vitamin E-deficient diet (group 12) serving as control. It can be seen that diets with $0.5 \%$ cystine (group 13), and $0.5 \%$ nordihydroguaiaretic acid (group 17 ), protected markedly against peroxidation and coloration of the adipose tissue as compared with the unsupplemented vitamin 


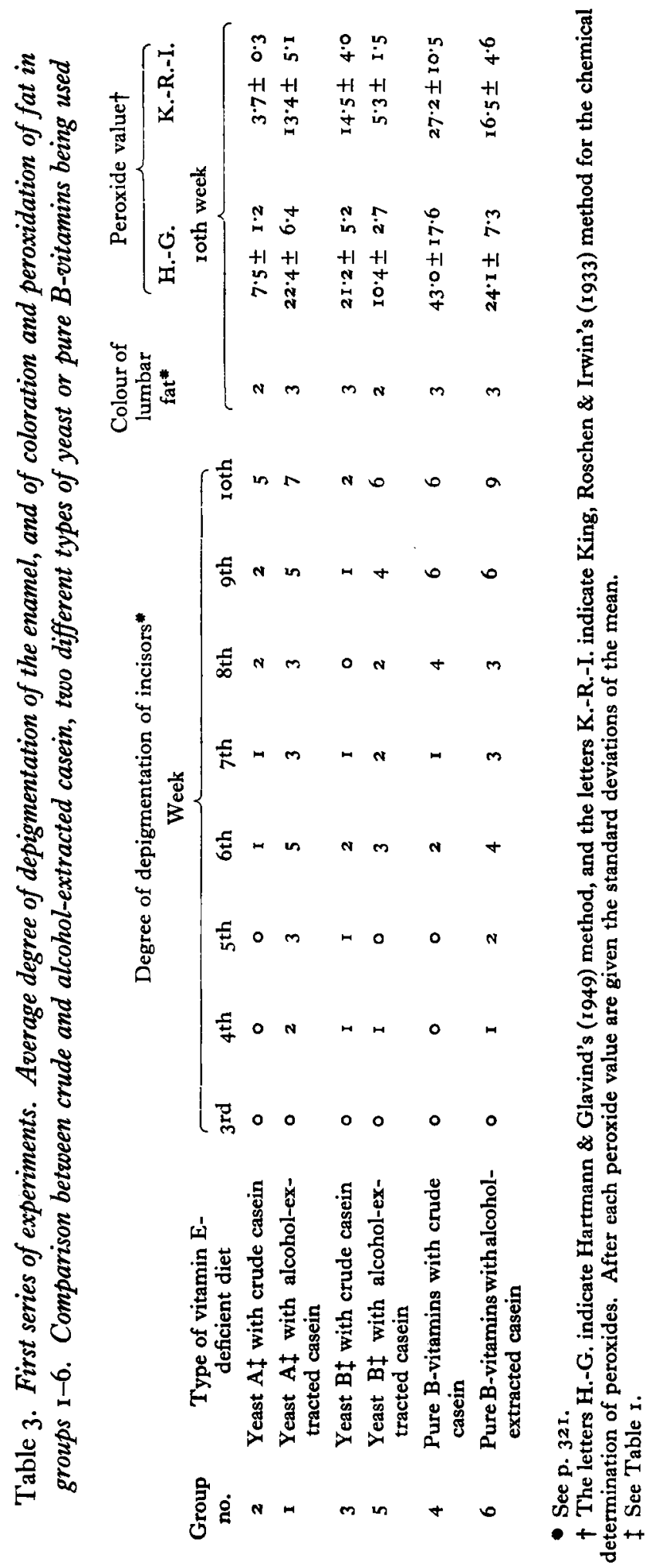




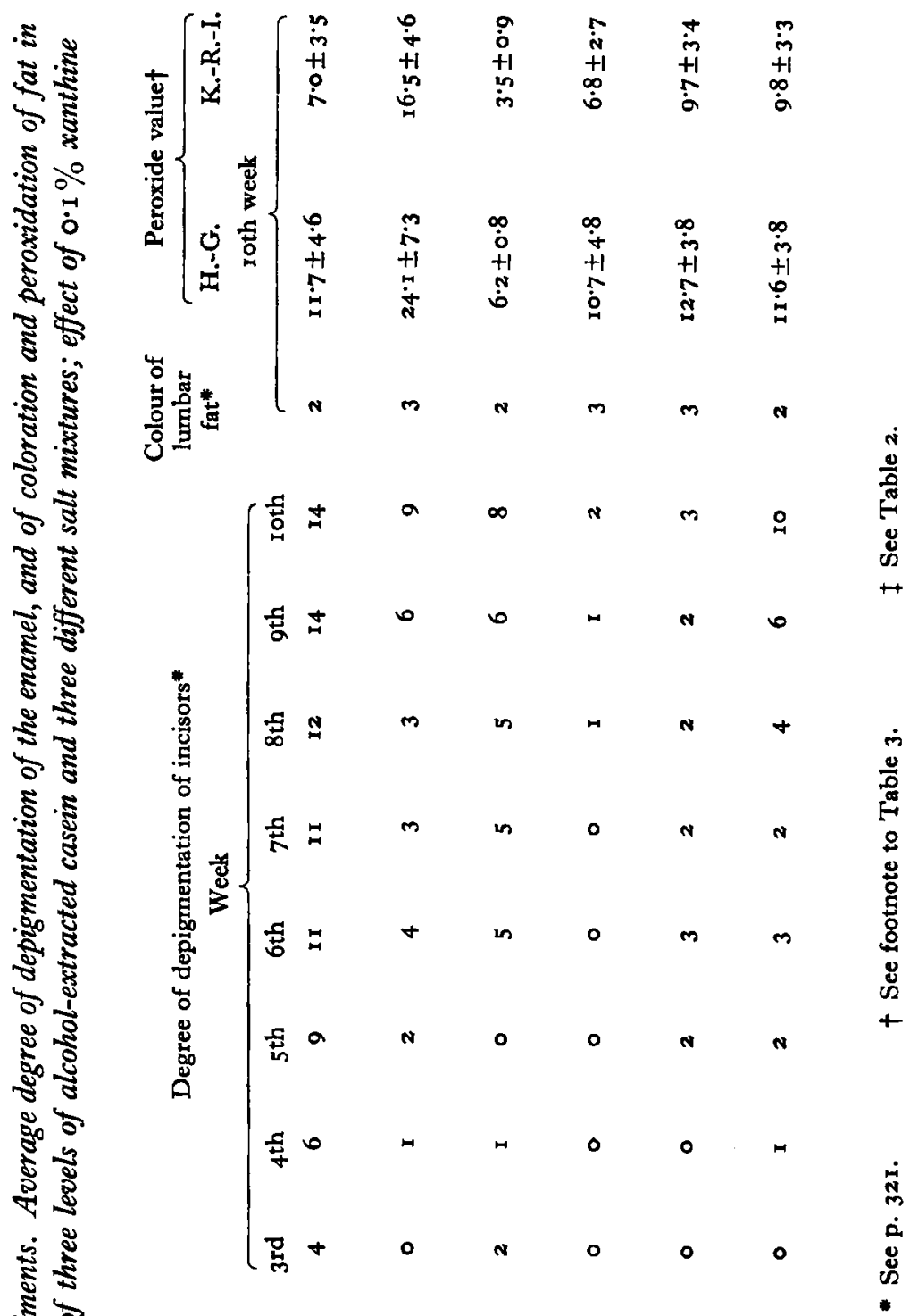

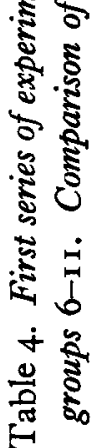

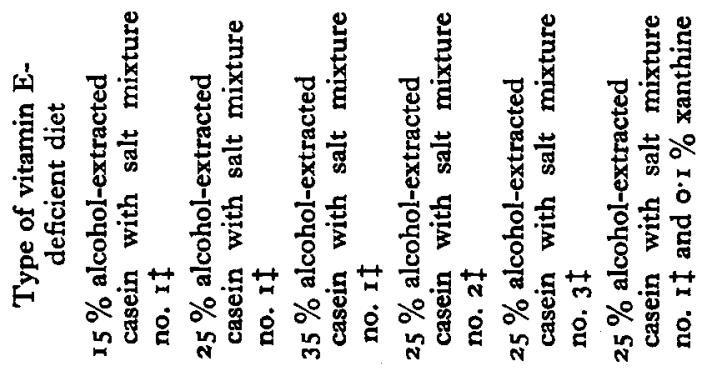

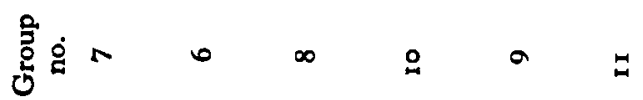


E-deficient diet (group I2). Methionine (0.6\%) (group I4), and $0.5 \%$ ascorbic acid (group I5) produced, to a lesser degree, a similar effect. Inositol (0.5\%) (group r6) slightly decreased fat peroxidation, but without protecting against coloration of the adipose tissue.

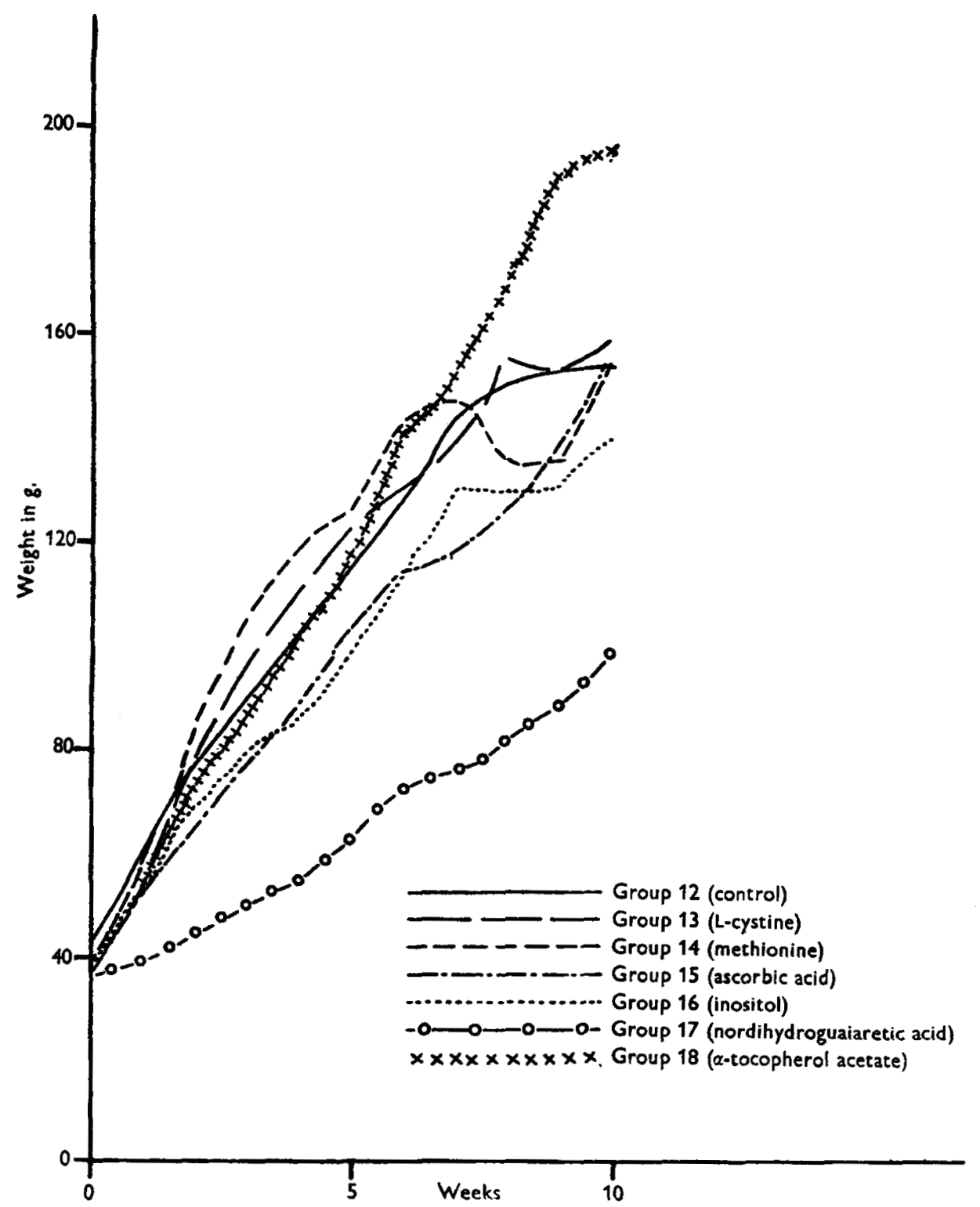

Fig. I. Average growth curves of groups $12-18$ in the second series of experiments.

On the other hand, Table 6 shows that nordihydroguaiaretic acid was the only substance other than tocopherol acetate, which offered very marked protection against tooth depigmentation.

Fig. I shows the average growth curves of groups 12-18. It can be seen that growth 


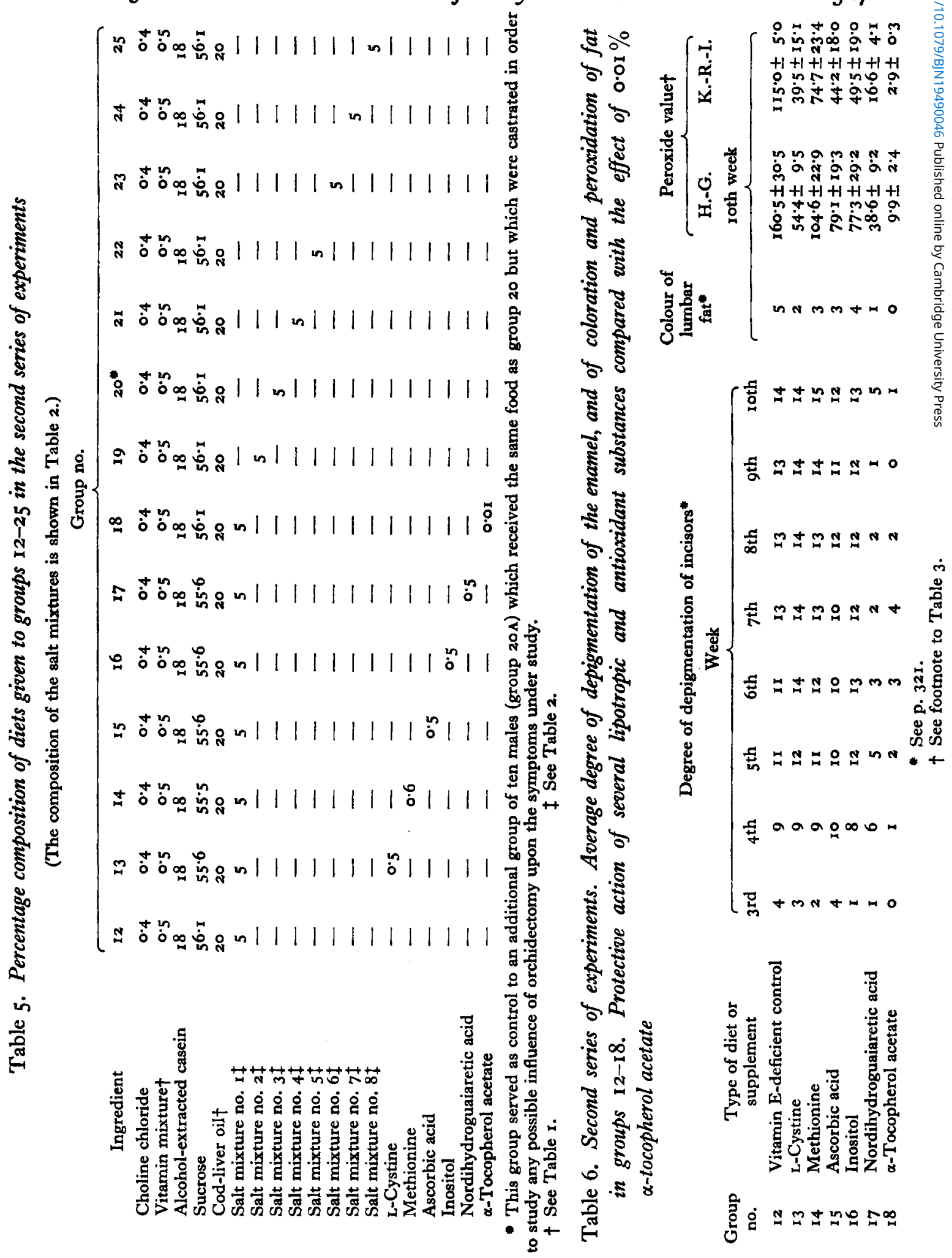


on diets with $0.5 \%$ cystine (group $\mathrm{I}_{3}$ ) and $0.6 \%$ methionine (group 14) was not significantly different from growth on the vitamin E-deficient diet (group 12);0.5\% ascorbic acid (group 15 ) retarded the growth rate but the final weight was the same as that of group 12; $0.5 \%$ inositol (group r6) decreased somewhat more the growth. More significant was the striking inhibition of growth produced by $0.5 \%$ nordihydroguaiaretic acid (group 17), which indicates a marked toxicity of this substance at the level given.

To ascertain more clearly which element or elements were responsible for the protective action of salt mixtures 2 and 3 against depigmentation of the teeth in the first series of experiments the following experiment was carried out, using a ration containing $18 \%$ alcohol-extracted casein.

Table 7 shows a comparison of the effect of McCollum's salt mixture 185 (group 12) with that of the same mixture supplemented as follows: iodine and manganese (group r9), iodine, manganese and copper (group 20), iodine and copper (group 21), manganese and copper (group 22), iodine (group 23), manganese (group 24), and copper (group 25). Only the animals which received salt mixtures containing manganese (groups 19, 20, 22 and 24) exhibited lower degrees of dental depigmentation. On the other hand, none of the supplements offered protection against peroxidation and discoloration of the adipose tissue.

As mentioned before (p. 32I), an additional group of ten males castrated at the beginning of the experiment (group 20A) was used in this study. The results (compared with those for group 20, Table 7) showed that castration influenced neither tooth depigmentation nor peroxidation or coloration of the adipose tissue. In connexion with this finding it should be mentioned that Kaunitz, Slanetz \& Atkinson (1949) noticed that in female rats ovariectomy prevents the formation of the brown pigmentation of the uterus originally observed by Martin \& Moore (1936).

Fig. 2 shows the average growth curves of groups 12 and $18-25$. It is apparent that three of the groups which received manganese, i.e. 19 (manganese and iodine), 20 (manganese, iodine and copper), and 24 (manganese) reached a final weight markedly higher than that of the group which received the unsupplemented McCollum's salt mixture 185 (group 12), and higher than those of the other supplemented groups. This indicates, therefore, that manganese alone, or combined with iodine, or with iodine and copper, produces an improvement of growth in vitamin E-deficient rats, a result not obtained when manganese is combined with copper alone (group 22).

Third series of experiments. Table 8 presents the diets fed to the seven groups of rats which comprise the last experiment reported in this paper. Table 9 compares the effects of no fat, lard and cod-liver oil given with a low level (10\%) of either crude or alcohol-extracted casein as the only source of protein. The results show that, in contrast to no fat; and lard which was harmless, with crude and with alcohol-extracted casein (groups 27 and 29), cod-liver oil with either casein (groups 28 and 30 ) produced some peroxidation and coloration of the adipose tissue.

Table 9 shows, further, a significant difference in the number of survivors between vitamin E-deficient animals which received no fat or lard (groups 27 and 29) and those given cod-liver oil (groups 28 and 30 ). It is clear that cod-liver oil induced a high per- 
Vol. 3

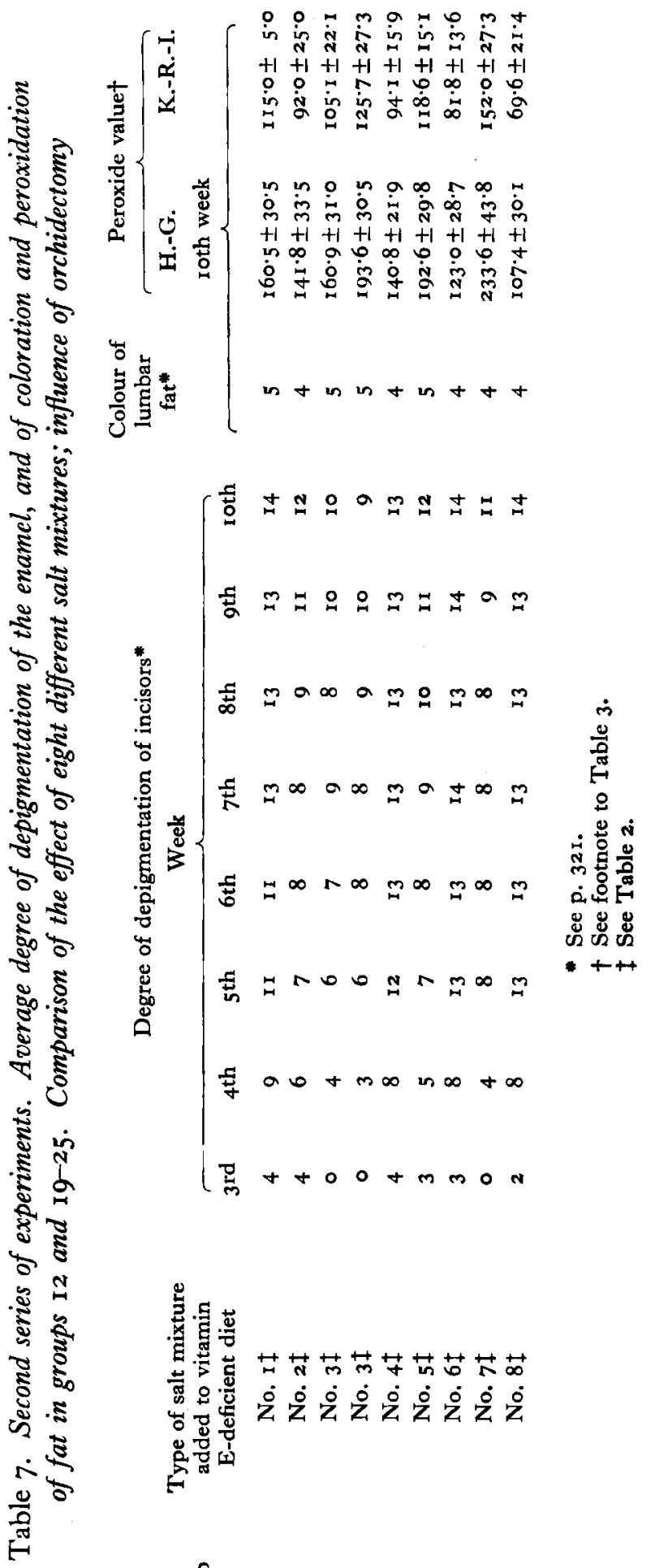

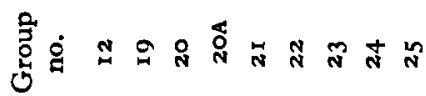


centage of deaths, whereas all the animals which received no fat or lard were alive at the end of the experimental period. The animals, given cod-liver oil, which died in the course of the experiment exhibited severe lung haemorrhage and gross liver

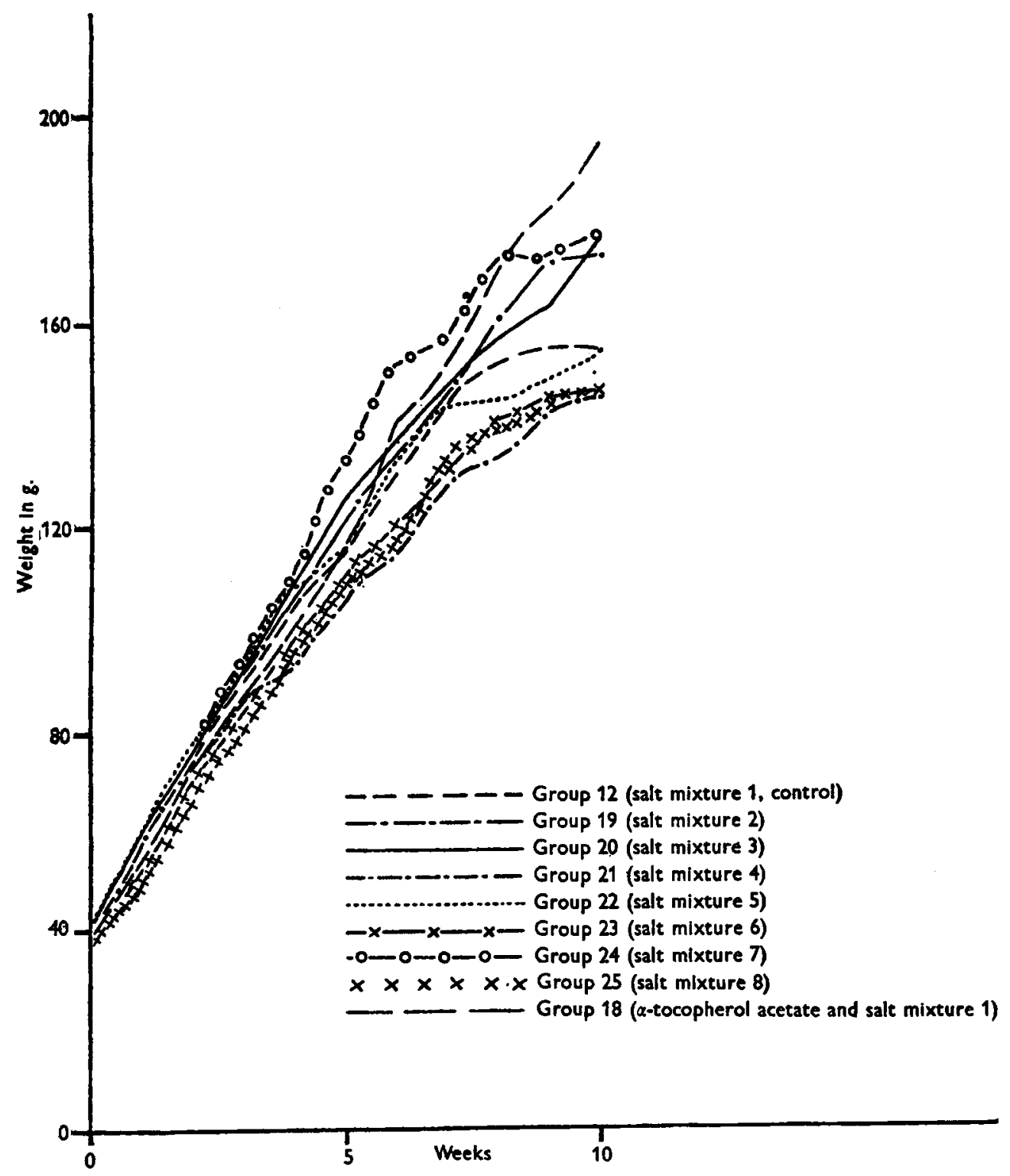

Fig. 2. Average growth curves of groups 12 , and $18-25$ in the second series of experiments.

damage with abnormal light areas of different size throughout the whole surface of the organ. In the animals given crude casein (group 28) there was some indication (Table 9) of a sex difference in the incidence of mortality, males having been more affected than females. The changes found by us are very similar to those recently 


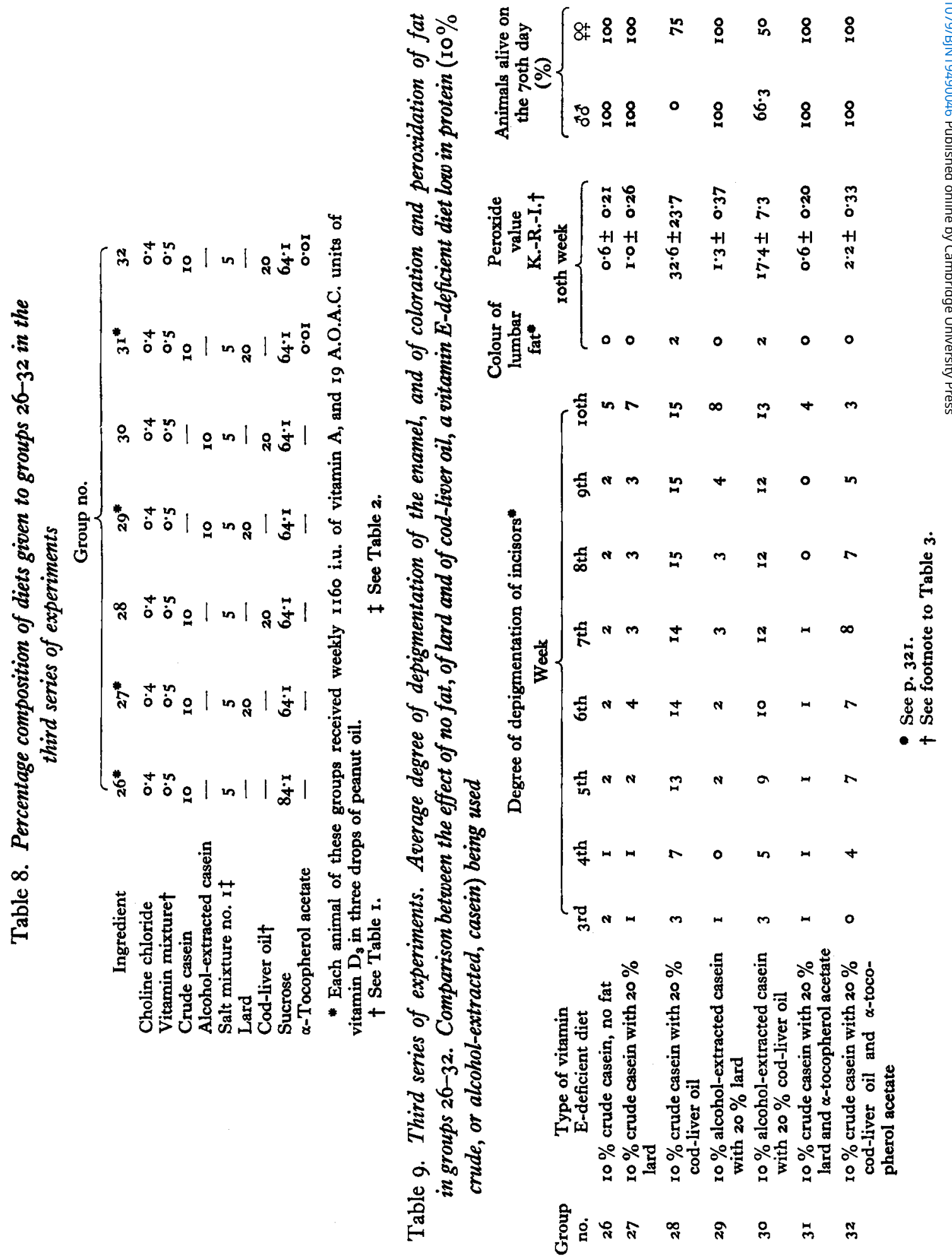


observed by Hove, Copeland \& Salmon (1949). However, we produced them only with $20 \%$ cod-liver oil, but not with $20 \%$ lard. This indicates that the pathological processes responsible for the early deaths of vitamin E-deficient rats given diets low in protein are related to abnormal metabolism of certain unsaturated fatty acids of dietary origin.

Finally, Table 9 demonstrates that a vitamin E-deficient diet without fat can produce a moderate degree of depigmentation of the enamel when the level of dietary protein is sufficiently low (group 26). At this protein level, lard accelerated tooth depigmentation (groups 27 and 29) to a significant degree, and even $0.01 \% \alpha$-tocopherol did not completely prevent it (group 32 ).

\section{DISCUSSION}

Table 3 showed that the groups which received crude instead of alcohol-extracted casein exhibited a partial protection against depigmentation of the enamel. This indicates that vitamin $\mathrm{E}$, or some other protective factor, contained in the crude casein may have been responsible for this action. Table 3 also showed that two groups may exhibit different degrees of depigmentation of the enamel but essentially the same degree of peroxidation and coloration of fat. Furthermore, it was noted that some animals may exhibit a marked degree of peroxidation and coloration of fat without any dental depigmentation. These facts show that the development and progress of depigmentation of the enamel may not run parallel to the peroxidation and coloration of the adipose tissue, and indicates that the dietary highly unsaturated fatty acids may bring about in the absence of vitamin $\mathrm{E}$ incisor depigmentation through some unknown mechanisms at least partly different from those which induce peroxidation and coloration of the adipose tissue.

Table 4 showed that a low level of dietary protein ( $15 \%$ ) induced a higher degree of dental depigmentation than high protein levels ( 25 and $35 \%$ ), without inducing simultaneously a higher degree of peroxidation and coloration of fat. This points again to the lack of consistent parallelism between depigmentation of the enamel and peroxidation and coloration of the adipose tissue. Furthermore, the fact that the rats which received $25 \%$ casein (group 6 ) exhibited more pronounced coloration of fat than those given either $15 \%$ (group 7 ) or $35 \%$ (group 8 ) casein suggests that the development of the fat changes may be most favoured at a certain level of dietary protein.

Table 4 also showed that $0.1 \%$ xanthine did not protect against any of the three symptoms under study. Furthermore, in this experiment, in which a dietary level of $25 \%$ casein was used, xanthine did not improve the growth of the animals. Hove \& Harris (1947) found that $0.1 \%$ xanthine increased the utilization of protein for growth by rats reared on a vitamin E-deficient diet low in protein (10\% casein), and Schwarz (1944) reported that xanthine could replace $\alpha$-tocopherol in preventing liver damage and delaying death in rats reared on an alkali-washed casein diet.

Table 6 showed that the antioxidants and the lipotropic substances tested decreased, to varying degrees, both peroxidation and coloration of the adipose tissue. It should be remarked, however, that a parallelism between decreased or increased peroxidation and coloration of the adipose tissue is not always to be found (Dam et al. 1949). From 
Table 6 it can be seen that especially nordihydroguaiaretic acid and L-cystine exhibited a marked protection against peroxidation and coloration of fat, similar to that effected by $\alpha$-tocopherol acetate. Furthermore, nordihydroguaiaretic acid was the only substance that offered a very marked protection against tooth depigmentation. This suggests that the production of depigmentation of the enamel and its prevention by certain antioxidants take place through mechanisms partly different from those which induce, or prevent, peroxidation and coloration of the adipose tissue.

Tables 4 and 7 showed that of the elements tested manganese alone was able to decrease tooth depigmentation. The fact that in the first experiment (Table 4), in which $25 \%$ casein was used, the salt mixtures containing manganese protected against enamel depigmentation to a higher degree than in the second experiment (Table 7), in which $18 \%$ casein was used, suggests that the ability of manganese to reduce depigmentation of the enamel may be related to the level of protein.

Table 9 showed that with a low protein level, cod-liver oil, but not lard, induced peroxidation and coloration of the adipose tissue. The same had been found with higher protein levels (Granados \& Dam, $1945 b$ ). On the other hand, it should be remarked that in group $3 \circ$ (Table 9) cod-liver oil with $10 \%$ casein induced a degree of peroxidation and coloration of fat markedly lower than that induced by the same level of cod-liver oil in combination with a higher level ( $18 \%$ ) of protein (group 12 in Table 7 , reared simultaneously with groups 26-32). This shows that the fat peroxidation and coloration brought about by highly unsaturated fatty acids in the absence of vitamin $\mathrm{E}$ is decreased by lowering the levels of dietary protein, and indicates that the mechanism through which the peroxidation and coloration of the adipose tissue are brought about is in some way linked with an abnormal metabolism of protein. In connexion with this finding it should be noted that Moore \& Wang (1947) suggested that the pigment of the uterus and certain other tissues in vitamin E deficiency may arise from an abnormal oxidation of protein, probably of tryptophan.

\section{SUMMARY}

x. Experiments were done to study further the influence of various nutrients on the development and progress of peroxidation and discoloration of the adipose tissue, and depigmentation of the incisors of vitamin E-deficient rats.

2. With 15,25 and $35 \%$ of casein in the diet depigmentation of the enamel was most pronounced, but peroxidation and discoloration of the fat were not increased, at the lowest level of protein.

3. Cystine $(0.5 \%)$ and nordihydroguaiaretic acid $(0.5 \%)$ protected markedly against peroxidation and coloration of the adipose tissue, but only the latter substance gave a significant protection against tooth depigmentation; $0.6 \%$ methionine, $0.5 \%$ ascorbic acid and $0.5 \%$ inositol protected to a lower degree against the changes in the adipose tissue. Nordihydroguaiaretic acid at the level given showed a marked toxic action through a striking inhibition of growth.

4. McCollum's salt mixture no. 185 supplemented with $556 \mathrm{mg} . \mathrm{MnSO}_{4} \cdot 4 \mathrm{H}_{2} \mathrm{O} /$ I0O g. partly protected against tooth depigmentation without protecting against the 
changes in the adipose tissue. Furthermore, manganese produced an improvement in growth as compared with that on a vitamin E-deficient diet in which McCollum's salt mixture no. 185 was left unsupplemented.

5. The peroxidation and coloration of the adipose tissue brought about by highly unsaturated fatty acids in the absence of vitamin $\mathrm{E}$ was decreased by lowering the level of dietary protein. This indicates that the mechanism through which these changes of the adipose tissue are brought about is linked with an abnormal protein metabolism.

6. A vitamin E-deficient diet without fat produced a moderate degree of depigmentation of the enamel when the protein was sufficiently low (10\% casein). At this level even $0.01 \%$ of $\alpha$-tocopherol did not completely prevent tooth depigmentation.

7. Orchidectomy influenced neither tooth depigmentation nor peroxidation or coloration of the adipose tissue in vitamin E-deficient rats.

8. Many rats in the groups reared on a vitamin E-deficient diet low (10\%) in protein and high $(20 \%)$ in cod-liver oil died in the course of the experiment with severe lung haemorrhage and gross liver damage. These changes, apparently similar to those recently reported by Hove et al. (1949), did not occur in a group reared on a similar ration devoid of fat, in groups given similar diets with the $20 \%$ cod-liver oil replaced by $20 \%$ lard or in groups given the above-mentioned rations supplemented with $0.01 \% \alpha$-tocopherol acetate.

This work was supported by a grant from Rask-Ørsted Fondet.

We thank F. Hoffmann-La Roche \& Co., Basle, Switzerland, for the gift of the DL- $x$-tocopherol acetate (Ephynal, Roche) used in these experiments.

Dam, H. (1944a). F. Nutrit. 27, 193.

Dam, H. (1944b). Y. Nutrit. 28, 297.

Dam, H. \& Granados, H. (1945a). Acta Physiol. scand. xo, I62.

Dam, H. \& Granados, H. (1945b). Science, 102, 327.

Dam, H., Granados, H. \& Prange, I. (1949). Acta Physiol. scand. 18, r6r.

Dam, H., Kruse, I., Prange, I. \& Søndergaard, E. (1948). Biochim. Biophys. Acta, 2, 50 .

Dam, H. \& Mason, K. E. (r945). Fed. Proc. 4, 153.

Glavind, J., Granados, H., Hartmann, S. \& Dam, H. (1949). Experientia, 5, 84.

Granados, H. \& Dam, H. (1945a). Science, ror, 250.

Granados, H. \& Dam, H. (1945b). Proc. Soc. exp. Biol., N.Y., 59, 295.

Granados, H. \& Dam, H. (1948). Odontol. Tidskr. 56, 457.

Granados, H., Glavind, J., Hartmann, S. \& Dam, H. (1950). Acta path. microbiol. scand. (In the Press.)

Granados, H., Mason, K. E. \& Dam, H. (1945). F. dent. Res. 24, 197.

Granados, H., Mason, K. E. \& Dam, H. (1946). F. dent. Res. 25, 179.

Granados, H., Mason, K. E. \& Dam, H. (1947). Acta Path. microbiol. scand. $24,86$.

Hartmann, S. \& Glavind, J. (1949). Acta chem. scand. 3, 954.

Hove, E. L., Copeland, D. H. \& Salmon, W. D. (1949). Fed. Proc. 8, 386.

Hove, E. L. \& Harris, P. L. (1947). F. Nutrit. 34, 571 .

Kaunitz, H., Slanetz, C. A. \& Atkinson, W. B. (1949). Proc. Soc. exp. Biol., N.Y., 70, 302.

King, A. E., Roschen, H. L. \& Irwin, W. H. (1933). Oil \&ீ Soap, ro, ro5.

Martin, A. J. P. \& Moore, T. (1936). F. Soc. chem. Ind., Lond., 55, 236.

Mason, K. E., Dam, H. \& Granados, H. (1946). Anat. Rec. 94, 265.

Moore, T. \& Wang, Y. L. (1947). Brit. F. Nutrit. r, 53.

Schwarz, K. (1944). Hoppe-Seyl. Z. 28r, 109. 